ORIGINAL ARTICLE

\title{
Oculocerebrocutaneous syndrome: the brain malformation defines a core phenotype
}

\author{
U Moog, M C Jones, L M Bird, W B Dobyns
}

J Med Genet 2005;42:913-921. doi: 10.1136/jimg.2005.031369

See end of article for authors' affiliations

Correspondence to

Dr Ute Moog, Department

of Clinical Genetics,

University Hospital

Maastricht, PO Box 5800,

6202 AZ Maastricht,

Netherlands; ute.moog@

gen.unimaas.nl

Received 25 January 2005

Revised version received

12 April 2005

Accepted for publication

18 April 2005 ndrome (OCCS) is characterised by orbital cysts and Background: Oculocerebrocutaneous syndrome (OCCS) is characterised by orbital cysts and
anophthalmia or microphthalmia, focal aplastic or hypoplastic skin defects, skin appendages, and brain malformations. The eye and skin abnormalities are well described but the neuropathological features less so. To date, 28 patients with an unequivocal diagnosis of OCCS have been reported, with a preponderance of males.

Objective: To evaluate the brain imaging studies, clinical records, photographs, and pathological material of two new and nine previously reported cases of OCCS.

Results: There was a consistent pattern of malformations in eight of the 11 cases, consisting of frontal predominant polymicrogyria and periventricular nodular heterotopia, enlarged lateral ventricles or hydrocephalus, agenesis of the corpus callosum sometimes associated with interhemispheric cysts, and a novel mid-hindbrain malformation. The latter consisted of a giant and dysplastic tectum, absent cerebellar vermis, small cerebellar hemispheres in most cases, and a large posterior fossa fluid collection.

Conclusions: The mid-hindbrain malformation appears pathognomonic for OCCS. The eye and skin features of OCCS show considerable overlap with several other syndromes, such as encephalocraniocutaneous lipomatosis, oculo-auriculo-vertebral spectrum, and focal dermal hypoplasia, none of which has a comparable pattern of brain malformations. In particular the unique mid-hindbrain malformation also distinguishes OCCS from related syndromes with comparable forebrain anomalies. The pattern of malformation described thus helps in differentiating OCCS from other entities. The mid-hindbrain malformation points to a defect of the mid-hindbrain organiser as the underlying pathogenic mechanism.
$\mathrm{O}$ culocerebrocutaneous syndrome (OCCS), also known as Delleman syndrome, is a rare multiple congenital anomaly-mental retardation syndrome characterised by the triad of eye, brain, and skin malformations, sometimes associated with other features such as craniofacial clefts, skull or rib defects, and urogenital anomalies. We have found reports of 28 patients with unequivocal OCCS, with a preponderance of affected males. ${ }^{12}$ These reports exclude patients with a possible diagnosis of OCCS or who have features of overlapping syndromes-in particular, encephalocraniocutaneous lipomatosis (ECCL) and oculoauriculovertebral spectrum (OAVS). The cause of OCCS is still unknown.

The eye malformations consist mainly of cystic anophthalmia or microphthalmia and colobomata, while the skin abnormalities consist of skin appendages and focal aplasia or hypoplasia. Both have been well described. ${ }^{1}$ Many reports mention cerebral cysts, but this might refer to several different anomalies such as arachnoid, porencephalic, or posterior fossa cysts, ventricular enlargement, or any other abnormal fluid collection. Several patients have had agenesis of the corpus callosum. However, many of the reports predate modern brain imaging methods and even recent reports rarely give a detailed description. A systematic description of the brain malformation in OCCS is not available. We therefore reviewed the brain abnormalities in a series of 11 patients with OCCS, using a variety of brain imaging studies and one necropsy report. While some of the images were old and incomplete, we were still able to document a remarkably consistent pattern of malformations that includes a novel mid-hindbrain malformation.

\section{METHODS}

We obtained all available data on the brain in 11 patients with OCCS, including medical records with reports of brain imaging studies, clinical photographs (fig 1), and all or portions of the original brain imaging studies (figs 2 and 3; see also the supplementary figures which can be viewed on the journal website: http://www.jmedgenet.com/ supplemental). The brain imaging studies included brain magnetic resonance imaging (MRI) in seven patients, cranial computed tomography (CT) in four, and pneumoencephalography (PEG) in one; one patient had both MRI and CT. We also reviewed a necropsy report and limited pathological tissue from the child who had PEG.

\section{RESULTS}

Clinical reports and review of brain abnormalities Patient 1

This boy was born with a large cystic left eye, right microphthalmia, eyelid colobomas and other ocular anomalies, and typical skin appendages. ${ }^{3}$ When re-evaluated at six years, he had severe mental retardation, intractable epilepsy, severe right hemiparesis, and decreased tactile sensation.

Brain MRI (figs 2 and 3, panels A-D) showed severe polymicrogyria with a very thick cortex in the left frontal, temporal, and perisylvian regions, at least one underlying periventricular nodular heterotopia $(\mathrm{PNH})$, enlarged lateral ventricles greater on the left, and agenesis of the corpus callosum. The midbrain was angled forward, resulting in a nearly horizontal aqueduct that abruptly enlarged into the fourth ventricle about half way down the midbrain. The midbrain tectum was massively enlarged ( to around $3 \mathrm{~cm}$ in

\footnotetext{
Abbreviations: DWM, Dandy-Walker malformation; ECCL, encephalocraniocutaneous lipomatosis; FDH, focal dermal hypoplasia; OAVS, oculoauriculovertebral spectrum; OCCS, oculocerebrocutaneous syndrome; PEG, pneumoencephalography; PMG, polymicrogyria; PNH, periventricular nodular heterotopia
} 

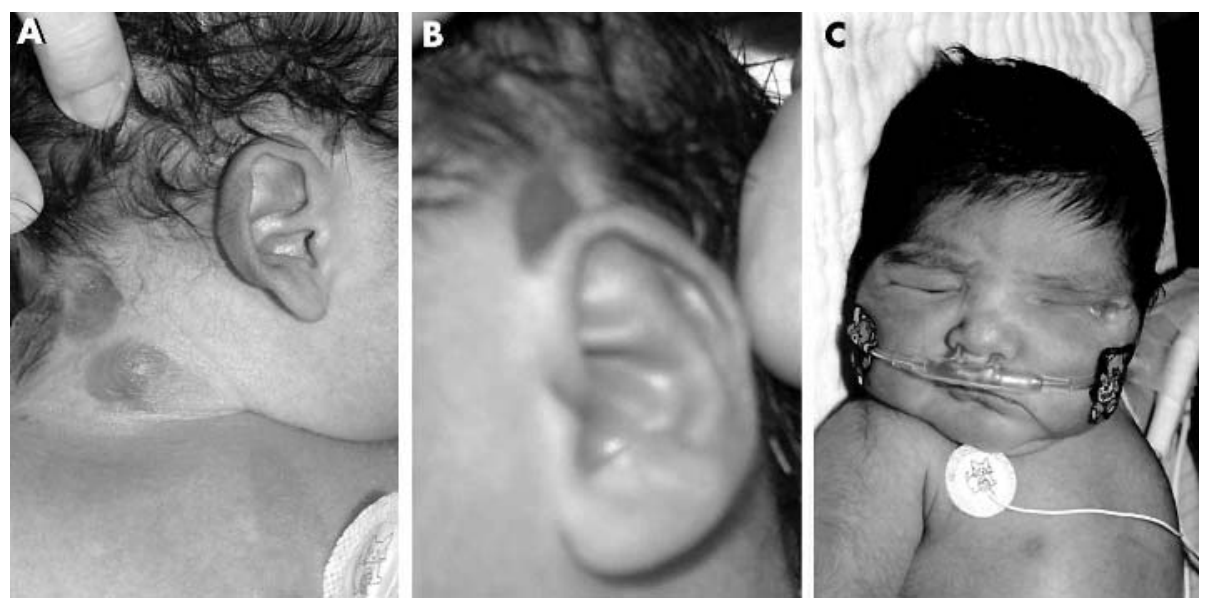

Figure 1 Clinical features of patients 2 and 3 . Note focal aplastic defects above the ears and blister-like lesions in patient 2 (A, B). Patient 3 (C) shows left microphthalmia, and a cleft and mass of tissue with a skin appendage in the left lower lid near the outer canthus. Written permission was obtained from the children's parents for the reproduction of these photographs.

length), rotated far upwards of the normal position behind the midbrain tegmentum, and indented inferiorly by the enlarging aqueduct into an arched shape. The superior cerebellar peduncles were long, thick, and straight, extending almost vertically downward to join the cerebellar hemispheres, which were almost normal in size. The cerebellar vermis was completely absent, although a small and unusual white matter tract connected the two hemispheres. The fourth ventricle was continuous with a large posterior fossa fluid collection, suggesting cystic enlargement. Similar images from a normal MRI study are shown for comparison in supplementary figure S1.

\section{Patient 2}

This boy was born to Mexican parents who were second cousins. His birth weight was $3.66 \mathrm{~kg}$, length $51 \mathrm{~cm}$, and head circumference $36 \mathrm{~cm}$. He had bilateral orbital cysts, a cleft left nostril with denuded skin, left macrostomia, multiple skin lesions, and right cryptorchidism. The skin lesions included a fleshy mass with tags and pits on the left cheek; tags in the middle of his forehead on top of a haemangioma, on his scalp to the left of the anterior fontanelle, and at the tip of the coccyx; a focal aplastic defect above the right and a crescent shaped one above the left ear (fig 1, panels A and B), another focal aplastic skin lesion just below the xyphoid process, and three deflated blister-like lesions on the right neck (fig lA). The left orbital cyst enlarged and was removed. Pathological examination showed malformed retinal and glial tissue with dystrophic calcifications. The mass on the cheek was also removed, together with a maxillary exostosis beneath it. Pathological examination confirmed a hamartoma. At one year, he had seizures and developmental delay.

Brain MRI at eight months (fig 3, panels E-H) showed asymmetrical polymicrogyria involving the frontal and perisylvian region, several periventricular nodular heterotopia along the anterior body of the left lateral ventricle, mildly enlarged ventricles, and agenesis of the corpus callosum. The polymicrogyria, periventricular nodular heterotopia, and ventricular enlargement were all more severe on the left. The upper midbrain was angled forward, resulting in a nearly horizontal aqueduct. The aqueduct was short, and abruptly enlarged into an extra ventricle just above the fourth ventricle. The tectum was again massively enlarged (to around $4 \mathrm{~cm}$ in length), rotated upward and curved, providing the roof of the extra ventricle. The cerebellar vermis was absent and the hemispheres were probably small from the limited images available. The fourth ventricle communicated with a large posterior fossa fluid collection.

\section{Patient 3}

This girl was born to a 33 year old Hispanic woman and her 32 year old unrelated husband. Her birth weight was $3.77 \mathrm{~kg}$, length $50 \mathrm{~cm}$, and head circumference $35 \mathrm{~cm}$. She had multiple anomalies including left microphthalmia, a disorganised mass of tissue with a skin appendage and cleft in the left lower lid near the outer canthus (fig 1C), and multiple skin lesions consisting of tags in the left nares, the periumbilical region, the right groin, and posterior to the anus; punched out aplastic defects in the left scalp and right heel; and multiple circumscribed hypoplastic defects with depression of subcutaneous tissue and lack of hair over the left leg. On pathological examination, the swelling near the left eye was a benign hamartoma with 46,XX chromosome constitution, while the hypoplastic skin defects were neuroectodermal developmental dysplasias. An omphalomesenteric duct remnant was found in the umbilical cord. Her heart was structurally normal but displaced in the chest by an anterior diaphragmatic eventration that was repaired. A few new skin lesions were seen during the first year, but not thereafter. Serial neurological examinations showed dysarthria, hypotonia, and a mild right hemiparesis. Cognitive functioning at three years was normal. An electroencephalogram was normal. Otoacoustic emission and sound field testing documented normal hearing bilaterally.

Brain MRI at one day (fig 3, panels I-L) showed asymmetrical polymicrogyria in the left frontal and perisylvian regions, possible polymicrogyria in the right frontal lobe, and mildly enlarged left lateral ventricle. No heterotopia were seen, but the resolution was low. The corpus callosum was dysmorphic with a thin body and absent splenium. The midbrain was angled slightly forward and the lower aqueduct was mildly enlarged. The midbrain tectum was enlarged (to around $1.5-2 \mathrm{~cm}$ ) but not rotated upward. The cerebellar vermis was absent and both hemispheres were small, especially the left. The fourth ventricle was large and communicated with a large posterior fossa fluid collection.

\section{Patient 4}

This boy was blind because of bilateral cystic anophthalmia, and had typical skin appendages. His case has been published in detail previously. ${ }^{14}$ At eight years, he had severe mental retardation and epilepsy. 

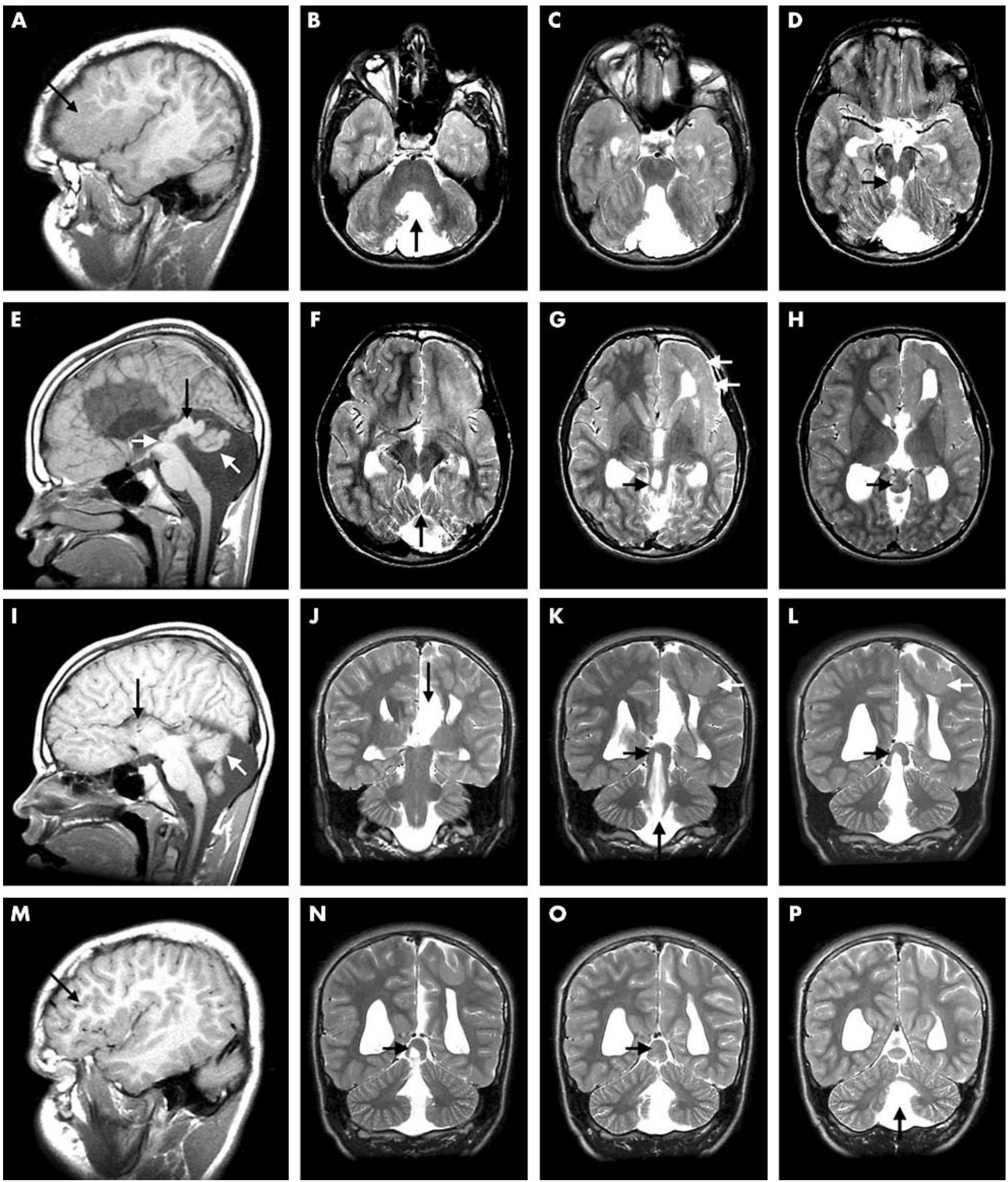

Figure 2 The classical brain malformation of the oculocerebrocutaneous syndrome (OCCS). Brain magnetic resonance imaging from patient 1 providing details of the OCCS brain malformation. Images through the cerebral hemispheres show an irregular surface, reduced sulcation, thick 10$15 \mathrm{~mm}$ cortex, and reduced white matter typical of polymicrogyria involving the left frontal, temporal, and parietal lobes (panels $\mathrm{F}-\mathrm{H}$, J-P, and white arrows in panels $\mathrm{G}, \mathrm{K}$, and L). The lateral ventricles are mildly enlarged, especially on the left, and the corpus callosum is absent (panels $\mathrm{E}$, I, and J; black arrows in panels I and J). Images through the posterior fossa show a massively enlarged tectum and absent cerebellar vermis. The midbrain tegmentum is flexed forward but otherwise normal. The aqueduct is short and nearly horizontal (horizontal white arrow in panel E), and enlarges into the fourth ventricle behind the upper midbrain. The fourth ventricle is continuous with a large posterior fossa fluid collection. The midbrain tectum is greatly enlarged (black arrows in panels $\mathrm{E}, \mathrm{H}$, and $\mathrm{O}$ ) and rotated upward; it appears to form an arch over the enlarged aqueduct (black arrows in panels $G, L$, and N). The cerebellar vermis is completely absent (panels B-G and L-P; black arrows in panels B, F, K, and P). The cerebellar hemispheres are nearly normal in size and seen in the midline because of the missing vermis (white arrow in panel E). The superior cerebellar peduncles are thick and dysplastic, descending vertically from the dysplastic midbrain to the cerebellar hemispheres (horizontal black arrow in panel K). The lower brain stem and spinal cord appear normal. 

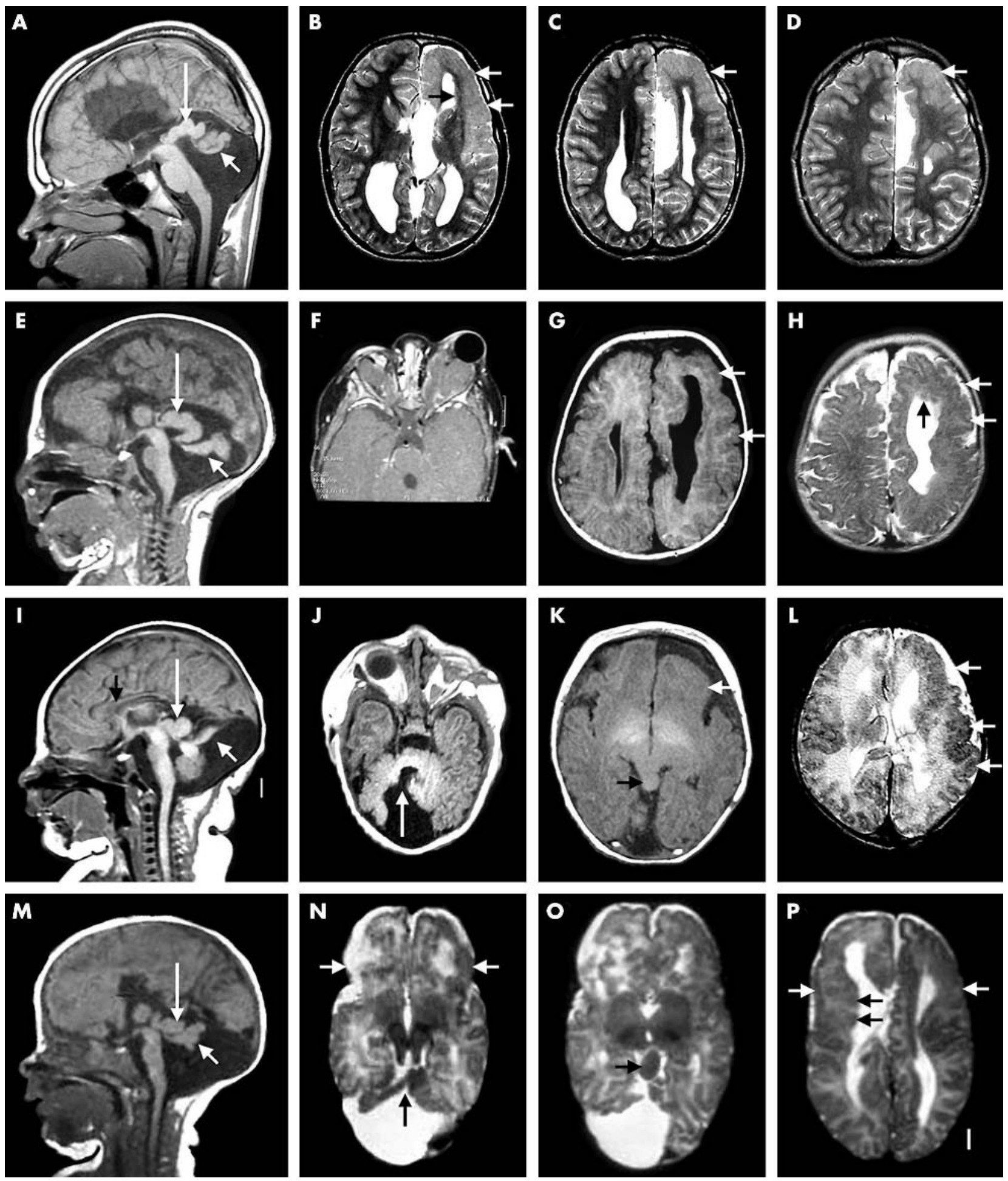

Figure 3 The classical brain malformation of the oculocerebrocutaneous syndrome (OCCS). Magnetic resonance imaging from patients 1 to 4 also demonstrates the typical OCCS brain malformation. Views of the cortex show polymicrogyria (horizontal white arrows in panels $B-D, G-H, K-L, a n d$ $N-P$ ), which is asymmetrical in all four patients, with more severe changes on the leff (the right side of the images) in patients 1 to 3 (panels $A-L$ ) and on the right in patient 4 (panels M-P). Several periventricular nodular heterotopia are seen adjacent to the frontal horns and anterior bodies of the lateral ventricles (black arrows inside the ventricles in panels $\mathrm{B}, \mathrm{H}$, and $\mathrm{P}$ ). The white matter is poorly myelinated in patients 2 to 4 (panels E-P) (patient 1 is older). The corpus callosum is absent in patients 1, 2, and 4 (panels A, E, and M), and dysplastic in patient 3 (black arrow in panel I). Images through the posterior fossa show a massively enlarged and upwardly rotated tectum (long white arrows in panels $A, E, I$, and M) and absent vermis (vertical arrows in panels $J$ and $\mathrm{N}$ ) in all four patients. In all, the midbrain is angled more forward than normal, leading to a short, horizontal aqueduct, enlarging prematurely into the fourth ventricle (panels A, I, and M) or appearing to form an abnormal extra ventricle behind the midbrain (panel E); the fourth ventricle is continuous with a large posterior fossa fluid collection. The cerebellar hemispheres are small and have a dysplastic foliar pattern in patients 3 and 4 (panels $J$ and $N$ ), and are seen in the midline because of the absent vermis (short white arrows in panels $A, E, I$, and M). 


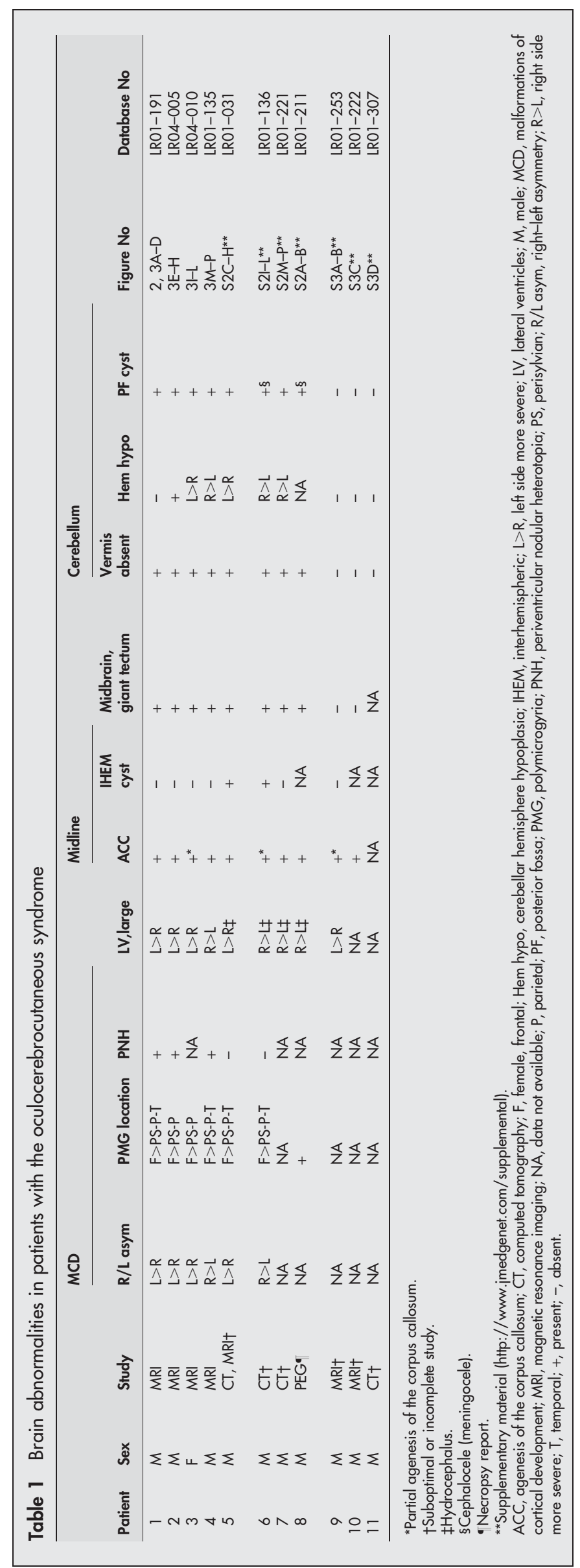


Brain MRI (fig 3, panels M-P) showed frontal polymicrogyria extending to the perisylvian, parietal, and temporal regions, periventricular nodular heterotopia along both frontal horns and lateral bodies of the lateral ventricles, mildly enlarged lateral ventricles, and complete agenesis of the corpus callosum. The cortical malformation was more severe on the right. The midbrain was anteverted, resulting in a nearly horizontal orientation of the aqueduct, which was mildly enlarged in its inferior portion. The tectum was moderately enlarged $(1.5-2 \mathrm{~cm})$ and round. The cerebellar vermis was absent and the hemispheres both very small. The fourth ventricle was continuous with a large posterior fossa fluid collection.

\section{Patient 5}

This boy had left cystic microphthalmia and eyelid coloboma, and typical skin lesions of OCCS. ${ }^{14}$ At 26 months, he had moderate mental retardation and epilepsy.

Brain MRI (supplementary fig S2, panels C-D) at seven months and later CT (supplementary fig S2, panels E-H) showed frontal polymicrogyria extending an uncertain distance posteriorly, more severe on the right. The lateral ventricles were enlarged, left more than right, and separated by several interhemispheric cysts posterior to the third ventricle-some with increased signal indicating lack of communication with the ventricles-suggesting total agenesis of the corpus callosum. Lower images showed an enlarged tectum with prominent and probably horizontal aqueduct, absent cerebellar vermis, moderate hypoplasia of the right and severe hypoplasia of the left cerebellar hemispheres, and a large posterior fossa fluid collection.

\section{Patient 6}

This boy was one of the original patients from the first report by Delleman et al, and was reported again at age 17 years. ${ }^{5-7}$ He presented with right cystic microphthalmia, bilateral eyelid coloboma, bilateral focal hypoplastic skin defects including a typical crescent shaped defect behind the ear, and skin appendages. He also had severe mental retardation.

Cranial CT (supplementary fig S2, panels I-L) done at ages four and seven years showed a thick and irregular cortex typical of polymicrogyria; this was present diffusely and was most severe in the smaller right frontal lobe. The lateral ventricles were asymmetrically enlarged with the right much larger than left, and separated by a midline cyst that appeared to be an extension of the third ventricle. The latter suggests partial agenesis of the corpus callosum. The midbrain was dysplastic with an enlarged aqueduct on one image and an unusual round mass of tissue on the highest image. The pons appeared mildly small, the vermis absent, and the cerebellar hemispheres small, especially on the right. A large fluid collection was located just behind the cerebellum and probably communicated with a low occipital skull defect, consistent with a meningocele.

\section{Patient 7}

This boy was patient 2 in the original paper reporting OCCS. ${ }^{56}$ He had bilateral cystic microphthalmia and eyelid colobomas, typical skin lesions, severe mental retardation, and a seizure disorder. He died at two years from complications of hydrocephalus.

Only low resolution CT from 1977 was available for review (supplementary fig S2, panels M-P), and the gyral pattern was too indistinct to assess. The lateral ventricles were mildly enlarged, more on the right, and widely separated, suggesting complete agenesis of the corpus callosum. The tectum was large and dysplastic, the vermis absent, and the cerebellar hemispheres hypoplastic, the right side being more severely affected. The midbrain appeared to connect to the cerebellar hemispheres directly. Serial scans were reported to show progressive hydrocephalus.

\section{Patient 8}

This German boy presented in the neonatal period with bilateral cystic anophthalmia, skin appendages in the periorbital region and on his trunk and the scalp, and numerous focal skin defects. He died aged one year. ${ }^{7}$

PEG done years ago (supplementary fig S2, panels A and B) showed asymmetrical, enlarged, and widely separated lateral ventricles typical of agenesis of the corpus callosum, probable hydrocephalus, a large posterior fossa fluid collection, and a skull defect in the occipital midline suggesting a meningocele. Necropsy showed polymicrogyria, hydrocephalus, an interhemispheric cyst, and a malformation of the midbrain tectum, which was $5 \mathrm{~cm}$ in length and extended beyond the cerebellum. We were able to obtain a single block of tissue from the cortex, most probably from the occipital lobe, which confirmed severe cortical dysplasia, although preservation was too poor to classify the type. Several intraabdominal neurofibromas were found along the sympathetic chain.

\section{Patient 9}

This three year old Belgian boy had eyelid and iris colobomas but no other eye anomalies, and atypical skin abnormalities consisting of small periorbital nodules, a small skin appendage on the thumb, and linear skin defects on the trunk and arms. ${ }^{8}$

A suboptimal and incomplete MRI (supplementary fig S3, panels A and B) showed a normal or possibly mildly dysplastic gyral pattern, enlarged and asymmetrical lateral ventricles, larger on the left, and partial agenesis of the corpus callosum with a small frontal remnant near the genu. Several loculated cysts with high signal (protein content) were seen within the lateral ventricles. The brain stem and cerebellum appeared grossly normal.

\section{Patient 10}

This Dutch boy had unilateral cystic microphthalmia, characteristic skin lesions, and mild mental retardation. He was also reported previously. ${ }^{9}$

The report of his MRI noted enlarged ventricles, but none of these images was available for review. A single midsagittal MRI (supplementary fig S3, panel C) showed a normal gyral pattern along the medial surface and total agenesis of the corpus callosum. The pons appeared moderately narrow or flat, but the midbrain, including the aqueduct and tectum, and the cerebellar vermis appeared normal.

\section{Patient 11}

This Russian baby was born with a huge anophthalmic orbital cyst on the left, which had already been diagnosed prenatally by ultrasound. He had typical skin lesions located on the left side or the midline. In addition, he had bilateral cryptorchidism and mild anomalies of the ribs. Apart from mild hypotonia, his psychomotor development was reported to be normal at two years. His case has been published in abstract. ${ }^{10}$ In addition, clinical data and photographs were available.

Cranial CT was reported as normal except for the eye. A single suboptimal image was available for review (supplementary fig S3, panel D). It showed a mildly enlarged space anterior to the left temporal pole, normal brain stem and cerebellum, and left cystic anophthalmia. 


\section{DISCUSSION}

OCCS is a rare malformation syndrome that hitherto has been diagnosed on the basis of the typical eye and skin abnormalities. We reviewed the brain abnormalities of 11 patients with OCCS which are summarised in table 1. Owing to the rarity of OCCS, we included patients ascertained over many years and as a result many of the available brain imaging studies were suboptimal and incomplete. We were able to review five patients in detail (patients 1 to 5), one adequately (patient 6), and five to a limited extent (patients 7 to 11). Despite this, we were able to document a remarkably consistent malformation in eight of the 11 patients and unexpectedly found a novel mid-hindbrain malformation. The three remaining patients had similar but less severe forebrain abnormalities, but lacked the mid-hindbrain malformation, which we suspect to be pathognomonic of OCCS.

\section{Typical OCCS brain malformation}

In the eight patients with the most typical malformation complex, the forebrain malformation consisted of: frontal predominant polymicrogyria; periventricular nodular heterotopia always located beneath the polymicrogyria; complete or partial agenesis of the corpus callosum, sometimes associated with interhemispheric cysts; and enlarged third and lateral ventricles complicated by hydrocephalus in four patients.

The novel mid-hindbrain malformation was found in all eight patients, and consisted of a giant tectum, absent vermis, and large posterior fossa fluid collection. The midbrain tegmentum was flexed forward, making the aqueduct nearly horizontal in four of the five patients with complete MRI studies. The giant and dysplastic tectum was rotated upward well above the normal position, and appeared to form an arch over the enlarged lower aqueduct in several patients. The cerebellar hemispheres were missing or hypoplastic with a dysplastic foliar pattern in seven of eight patients. The fourth ventricle communicated widely with a large posterior fossa fluid collection, sometimes associated with an occipital meningocele. These anomalies, excluding the midline malformations, were asymmetrical in all eight patients. The more severe polymicrogyria, more numerous periventricular nodular heterotopia, larger lateral ventricles, and smaller cerebellar hemispheres were always on the same side when we could assess this.

The key forebrain malformations of polymicrogyria, periventricular nodular heterotopia, enlarged ventricles, and agenesis of the corpus callosum are relatively common individually, but occur together in only a few syndromes, as we will review. Thus this pattern should be very helpful for diagnosis. The mid-hindbrain malformation has previously been confused with typical Dandy-Walker malformation (DWM), which should not be surprising. The usual diagnostic criteria for DWM include hypoplasia of the cerebellar vermis and a widely open fourth ventricular outflow tract communicating with a large posterior fossa fluid collection, or so called cystic enlargement of the fourth ventricle. ${ }^{11}{ }^{12}$ While the typical OCCS mid-hindbrain malformation described here includes each of these criteria and so could be labelled DWM, we think this would lead to diagnostic confusion. The OCCS mid-hindbrain malformation includes many other anomalies and is clearly much more severe and complex than DWM. Despite considerable experience in evaluating brain malformations in many different disorders, we have not seen this mid-hindbrain malformation in any other context. We hypothesise that all or most patients with giant tectum-absent vermis malformation have OCCS, and that most but not all patients with OCCS have the midhindbrain malformation.

\section{Incomplete OCCS brain malformations}

Only suboptimal imaging studies were available for the remaining three OCCS patients, but at least two had agenesis of the corpus callosum and none had the mid-hindbrain malformation. The gyral pattern and cortex were either normal or mildly dysplastic in patient 9, but resolution of the MRI was too low to be sure. This could not be assessed in the other two patients. Patient 9 also had mildly enlarged lateral ventricles with several cysts within them that appeared quite different from the midline cysts seen in two patients from the more typical OCCS group. Two of the three (Nos 10 and 11) had typical eye and skin changes of OCCS, although patient 10 was less severely affected than any of the others. In contrast, patient 9 had atypical linear skin defects with unusual localisation. However, one patient with less typical eye and skin lesions was also found in the group with the typical brain phenotype. We do not yet have enough evidence to determine whether OCCS in these three patients results from the same cause as OCCS in more typical patients.

\section{The differential diagnosis of OCCS}

Our results have implications for the differential diagnosis of several related syndromes. Some have overlapping eye and skin changes such as ECCL, OAVS, and focal dermal hypoplasia (FDH or Goltz syndrome). Others have similar brain malformations, especially Aicardi syndrome and a recently recognised group of syndromes with periventricular nodular heterotopia and polymicrogyria.

ECCL and OAVS have considerable overlap with OCCS with regard to the skin, eye, and other associated abnormalities. Extensive lipomatosis of the brain and spinal cord are characteristic of ECCL. ${ }^{13}$ In addition, asymmetries of the cerebral hemispheres, an abnormal gyral pattern, cortical calcifications, porencephalic or arachnoid cysts, and dilated lateral ventricles have been described repeatedly. ${ }^{14-17}$ However, mid-hindbrain malformation has never been described in ECCL. In OAVS, only a minority of the patients have developmental delay. A few have hydrocephalus or various brain malformations, but no pattern has emerged except that patients with microphthalmia, clefts, or other evidence of a severe phenotype are more likely to have developmental problems. ${ }^{18}$ Several patients with (possible) OCCS and overlap with OAVS have been reported. ${ }^{19-22}$ One boy had polymicrogyria over the frontal lobes, agenesis of the corpus callosum, and a midline cyst and so probably had OCCS..$^{20}$ Several other patients with overlapping features of OAVS and OCCS have had massive hydrocephalus without the brain anomalies characteristic of OCCS. In this group, the combination of severe hydrocephalus with anophthalmia or severe microphthalmia and clefts favours OAVS.

$\mathrm{FDH}$ is an $\mathrm{X}$ linked disorder mainly affecting females characterised by a combination of cutaneous, ocular, neurological, and skeletal features. ${ }^{23}$ Focal hypoplastic skin lesions, often with herniation of fatty tissue, and linear pigmentation are the predominant cutaneous features. In contrast to OCCS, the skin lesions commonly follow the lines of Blaschko, indicating a mosaic defect. Skin tags are papillomas in contrast to the (mostly periorbital) hamartomatous tags in OCCS. Ocular features are very diverse and mostly affect the anterior chamber; chorioretinal and iris colobomas are reported but orbital cysts have not been described. Skeletal defects of the hands and feet may occur. Radiography shows striation of the bones in most patients. Whereas many patients are mentally retarded, brain malformations have rarely been described and do not correspond to the brain malformations seen in OCCS. 


\section{Aicardi syndrome}

The typical OCCS brain malformation overlaps substantially with the brain malformation seen in Aicardi syndrome, which is thought to be X linked with embryonic lethality in males. Although the typical eye anomalies (chorioretinal lacunae) are different and the skin generally is normal, other features of Aicardi syndrome overlap considerably with OCCS. For example, the brain malformations in Aicardi syndrome include polymicrogyria, rare periventricular nodular heterotopia, enlarged ventricles (but not typically hydrocephalus), and agenesis of the corpus callosum. ${ }^{24}$ Interestingly, a few patients with Aicardi syndrome had DWM. ${ }^{26}$ Other overlapping features include microphthalmia, coloboma of the optic nerve, scalp lipoma, cleft lip/palate, and costovertebral defects.

\section{PNH-PMG syndromes}

We have recently delineated several syndromes with polymicrogyria, periventricular nodular heterotopia, and other anomalies (Dobyns WB, unpublished data). The frontalperisylvian subtype consists of periventricular nodular heterotopia lining the lateral body and frontal horns of the lateral ventricles, overlying polymicrogyria that is most severe in the perisylvian area, and sometimes agenesis of the corpus callosum and mild cerebellar vermis hypoplasia. The malformation is usually symmetrical, and no other anomalies have been observed. A posterior subtype consists of periventricular nodular heterotopia of the temporal horns, trigones, and occipital horns of the lateral ventricles, overlying polymicrogyria most severe in the temporal, parietal, and occipital lobes, and frequent agenesis of the corpus callosum and hypoplasia of the entire cerebellum. This malformation complex is usually asymmetrical, but again no other anomalies have been found; in particular, the midhindbrain malformation described in this paper has not been present.

\section{Pathogenesis of OCCS}

Analysis of available data regarding the pathogenesis of OCCS provides two important clues, both of which support a genetic aetiology for OCCS despite the lack of familial recurrence. First, a striking preponderance of males has been reported, including 10 of the 11 patients reported here. The only female in our series had the typical brain malformation, which suggests that she has the same syndrome. Among the six other female patients reported, one did not undergo brain imaging, ${ }^{6}$ one had normal cranial $\mathrm{CT}^{27}$ and four had malformations that may fit the classical brain phenotype. ${ }^{28-31}$ These data suggest that OCCS may be $\mathrm{X}$ linked.

Second, the unusual mid-hindbrain malformation suggests an abnormality of the isthmus organiser, which is located between the embryonic midbrain and the first segment of the hindbrain (rhombomere l or Rhl) and controls the development of the midbrain, upper pons, and cerebellum. Recent experimental data in the mouse show that two transcription factors (the rostrally expressed Otx2 gene and the caudally expressed Gbx2 gene) repress each others' expression, forming a sharp boundary between the midbrain and Rhl. This establishes the position of the developmental signalling centre for this region and ultimately defines the posterior limit of the midbrain and the anterior limit of the cerebellum..$^{32-34}$ One possible interpretation of the giant tectum-absent vermis malformation in OCCS is that the boundary between the midbrain and hindbrain has been shifted caudally in the dorsal portion of the embryonic neural tube, which is less extensive than observed in Gbx2 knockout mice and so appears provisionally unique.

\section{Conclusion}

The reported pattern of brain malformations in patients with OCCS extends the phenotype and should prove very useful in establishing the diagnosis and differentiating it from other entities, in particular from syndromes with overlapping skin and eye features. These observations should contribute to unravelling the underlying pathogenic mechanism. The novel mid-hindbrain malformation points to a defect in early pattern formation at the stage when the isthmus organising centre is established, setting up the boundary of the midbrain and cerebellum.

\section{ACKNOWLEDGEMENTS}

We thank Jeffrey Golden, University of Pennsylvania School of Medicine and the Children's Hospital of Philadelphia, for pathological review in patient 8 .

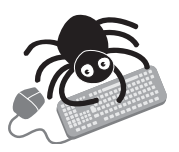

The supplementary figures can be viewed on the journal website at http://www.jmedgenet.com/ supplemental

\section{Authors' affiliations}

U Moog, Department of Clinical Genetics, University Hospital Maastricht, Maastricht University, Maastricht, Netherlands M C Jones, L M Bird, Department of Dysmorphology and Genetics, Children's Hospital San Diego, San Diego, California, USA W B Dobyns, Departments of Human Genetics, Neurology and Pediatrics, The University of Chicago, Chicago, Illinois, USA

Competing interests: none declared

\section{REFERENCES}

1 Moog U, de Die-Smulders C, Systermans JMJ, Cobben JM. Oculocerebrocutaneous syndrome: report of three additional cases and aetiological considerations. Clin Genet 1997;52:219-25.

2 Tambe KA, Ambekar SV, Bafna PN. Delleman (oculocerebrocutaneous) syndrome: few variations in a classical case. Eur J Paediatr Neurol 2003;7:77-80.

3 Pasquale LR, Romayananda N, Kubacki J, Johnson MH, Chan GH. Congenital cystic eye with multiple ocular and intracranial anomalies. Arch Ophthalmol 1991;109:985-7.

4 Naafs GG, van der Vliet AM, Hew JM. The oculocerebrocutaneous (DellemanOorthuys) syndrome. Neuroradiology 1999;41:55-9.

5 Delleman JW, Oorthuys JWE. Orbital cyst in addition to congenital cerebral and focal dermal malformations: a new entity? Clin Genet 1981;19:191-8.

6 Delleman JW, Oorthuys JWE, Bleeker-Wagemakers EM, ter Haar BGA, Ferguson JW. Orbital cyst in addition to congenital cerebral and focal dermal malformations: a new entity. Clin Genet 1984;25:470-2.

7 Moog U, Kruger G, Stengel B, de Die-Smulders C, Dykstra S, BleekerWagemakers E. Oculocerebrocutaneous syndrome: a case report, a follow-up, and differential diagnostic considerations. Genet Couns 1996;7:257-65.

8 Narbay G, Meire F, Verloes A, Casteels I, Devos E. Ocular manifestations in Delleman syndrome (oculocerebrocutaneous syndrome, OCC-syndrome) and encephalocraniocutaneous lipomatosis (ECCL). Bull Soc Belg Ophtalmol 1996;261:65-70.

9 Hennekam RCM, Beemer FA, Bleeker-Wagemakers LM, Hamel BCJ, Oorthuys HWE. Oculocerebrocutaneous syndrome. J Med Genet 1990;27:69-70.

10 Naumchik I, llyina H, Rumantseva N. Delleman syndrome, a new case report. Medizinische Genetik 1996;8:42.

11 Boddaert N, Klein O, Ferguson N, Sonigo P, Parisot D, Hertz-Pannier L, Baraton J, Emond S, Simon I, Chigot V, Schmit P, Pierre-Kahn A, Brunelle F. Intellectual prognosis of the Dandy-Walker malformation in children: the importance of vermian lobulation. Neuroradiology 2003;45:320-4.

12 Parisi MA, Dobyns WB. Human malformations of the midbrain and hindbrain: review and proposed classification scheme. Mol Genet Metab 2003:80:36-53.

13 Alfonso I, Lopez PF, Cullen RF, Martin-Jimenez R, Bejar RL. Spinal cord involvement in encephalocraniocutaneous lipomatosis. Pediatr Neurol 1986;2:380-4.

14 Bamforth JS, Riccardi VM, Thisen P, Chitayat D, Friedman JM, Caruthers J, Hall JG. Encephalocraniocutaneous lipomatosis: report of two cases and review of the literature. Neurofibromatosis 1989;2:166-73.

15 Grimalt R, Ermacora E, Mistura L, Russo G, Tadini GL, Triulzi F, Cavicchini S, Rondanini GF, Caputo R. Encephalocraniocutaneous lipomatosis: case report and review of the literature. Pediatr Dermatol 1993; 10:164-8. 
16 Nowaczyk MJ, Mernagh JR, Bourgeois JM, Thompson PJ, Jurriaans E. Antenatal and postnatal findings in encephalocraniocutaneous lipomatosis. Am J Med Genet 2000;91:261-6.

17 Parazzini C, Triulzi F, Russo G, Mastrangelo M, Scotti G Encephalocraniocutaneous lipomatosis: complete neuroradiologic evaluation and follow-up of two cases. Am J Neuroradiol 1999;20:173-6.

18 Schrander-Stumpel CT, de Die-Smulders CE, Hennekam RC, Fryns JP, Bouckaert PX, Brouwer OF, da Costa JJ, Lommen EJ, Maaswinkel-Mooy PD. Oculoauriculovertebral spectrum and cerebral anomalies. J Med Genet 1992;29:326-31.

19 Leichtman LG, Wood B, Rohn R. Anophthalmia, cleft lip/palate, facial anomalies, and CNS anomalies and hypothalamic disorder in a newborn: a midline developmental field defect. Am J Med Genet 1994;50:39-41.

20 Angle B, Hersh JH. Anophthalmia, intracerebral cysts, and cleft lip/palate: expansion of the phenotype in oculocerebrocutaneous syndrome? Am J Med Genet 1997;68:39-42.

21 Ming JE, Katowitz J, McDonald-McGinn DM, Schnur RE, Hunter JV, Zackai EH. Hemifacial microsomia in a newborn with hypoplastic skin lesions, an eyelid tag, and microphthalmia: an unusual presentation of Delleman syndrome. Clin Dysmorphol 1998;7:279-83.

22 McCandless SE, Robin NH. Severe oculocerebrocutaneous (Delleman) syndrome: overlap with Goldenhar anomaly. Am J Med Genet 1998;78:282-5

23 Goltz RW. Focal dermal hypoplasia syndrome: an update. Arch Dermatol 1992; 128:1108-11.
24 Hall-Craggs MA, Harbord MG, Finn JP, Brett E, Kendall BE. Aicardi syndrome: MR assessment of brain structure and myelination. Am J Neuroradiol 1990;11:532-6.

25 Barkovich AJ, Simon EM, Walsh CA. Callosal agenesis with cyst. A better understanding and new classification. Neurology 2001:56:220-7.

26 Jageerhussain M, Dhinagar S, Nadaradjan S, Bhat BV. Aicardi syndrome with Dandy-Walker malformation. Indian Pediatr 2000;37:673-6.

27 Clericuzio C. Oculocerebrocutaneous syndrome and the family of neurodermal disorders: developmental considerations. Proc Greenwood Genet Cent 1990:9:74.

28 Wilson RD, Traverse L, Hall JG, Flodmark CO, Rootman J. Oculocerebrocutaneous syndrome. Am J Ophthalmol 1985;99:142-8.

29 Al-Gazali LI, Donnai D, Berry SA, Say B, Mueller RF. The oculocerebrocutaneous (Delleman) syndrome. J Med Genet 1988;25:773-8.

30 Giorgi PL, Gabrielli O, Catassi C, Coppa GV. Oculo-cerebro-cutaneous syndrome: description of a new case. Eur J Pediatr 1989;148:325-6.

31 De Cock R, Merizian A. Delleman syndrome: a case report and review. Br J Ophthalmol 1992:76:115-16.

32 Chizhikov V, Millen KJ. Development and malformations of the cerebellum in mice. Mol Genet Metab 2003;80:54-65.

33 Simeone A. Positioning the isthmic organizer where Otx2 and Gbx2 meet. Trends Genet 2000;16:237-40.

34 Wurst W, Bally-Cuif L. Neural plate patterning: upstream and downstream of the isthmic organizer. Nat Rev Neurosci 2001 ;2:99-108.

\section{bmjupdates+}

bmjupdates+ is a unique and free alerting service, designed to keep you up to date with the medical literature that is truly important to your practice.

bmjupdates+ will alert you to important new research and will provide you with the best new evidence concerning important advances in health care, tailored to your medical interests and time demands.

\section{Where does the information come from?}

bmiupdates+ applies an expert critical appraisal filter to over 100 top medical journals A panel of over 2000 physicians find the few 'must read' studies for each area of clinical interest

Sign up to receive your tailored email alerts, searching access and more...

www.bmjupdates.com 
PHF6 mutation also found in the original Borjeson-Forssman-Lehmann syndrome family. Eur J Hum Genet 2004; 12:787-9.

4 Turner G, Lower KM, White SM, Delatycki M, Lampe AK, Wright M, Smith JC, Kerr B, Schelley S, Hoyme HE, De Vries BB, Kleefstra T, Grompe M, Cox B, Gecz J, Partington $M$. The clinical picture of the Borieson-Forssman-Lehmann syndrome in males and heterozygous females with PHF6 mutations. Clin Genet 2004;65:226-32

5 Plenge RM, Stevenson RA, Lubs HA, Schwartz CE, Willard HF. Skewed Xchromosome inactivation is a common feature of $X$-linked mental retardation disorders. Am J Hum Genet 2002:71:168-73.

6 Allen RC, Zoghbi HY, Moseley AB, Rosenblatt HM, Belmont JW. Methylation of Hpall and Hhal sites near the polymorphic CAG repeat in the human androgen-receptor gene correlates with $\mathrm{X}$ chromosome inactivation. Am J Hum Genet 1992;51:1229-39.

7 Carrel L, Willard HF. An assay for X inactivation based on differential methylation at the fragile X locus, FMR1. Am J Med Genet 1996;64:27-30.

8 van Kamp H, Jansen R, Willemze R, Fibbe WE, Landegent JE. Studies on clonality by PCR analysis of the PGK-1 gene. Nucleic Acids Res $1991 ; 19: 2794$.

9 Thouin MM, Giron JM, Hoffman EP. Molecular analysis of genetic identity. In: Dracopoli NC, Haines JL, Korf BR, et al, editors. Current protocols in human genetics, vol 2. New York: John Wiley and Sons, 2002:9.7.1-6.

10 Baumstark A, Lower KM, Sinkus A, Andriuskeviciute I, Jurkeniene L, Gecz J, Just W. Novel PHF6 mutation p.D333del causes Borjeson-Forssman-Lehmann syndrome. J Med Genet 2003;40:e50.
11 Vallee D, Chevrier E, Graham GE, Lazzaro MA, Lavigne PA, Hunter AG, Picketts DJ. A novel PHF6 mutation results in enhanced exon skipping and mild Borjeson-Forssman-Lehmann syndrome. J Med Genet 2004;41:778-83.

12 Pagani $F$, Baralle FE. Genomic variants in exons and introns: identifying the splicing spoilers. Nat Rev Genet 2004;5:389-96.

13 Cooper DN, Youssoufian H. The CpG dinucleotide and human genetic disease. Hum Genet 1988;78:151-5.

14 Visootsak J, Rosner B, Dykens E, Schwartz C, Hahn K, White SM, Szeftel R, Graham JM. Clinical and behavioral features of patients with BorjesonForssman-Lehmann syndrome with mutations in PHF6. J Pediatr 2004; 145:819-25.

15 Braunschweig D, Simcox T, Samaco RC, LaSalle JM. X-Chromosome inactivation ratios affect wild-type MeCP2 expression within mosaic Rett syndrome and Mecp2-/+ mouse brain. Hum Mol Genet 2004;13:1275-86.

16 Weaving LS, Ellaway CJ, Gecz J, Christodoulou J. Rett syndrome: clinical review and genetic update. J Med Genet 2005;42:1-7.

17 Matsuo K, Murano I, Kajii T. Borjeson-Forssman-Lehmann syndrome in a girl. Jinrui Idengaku Zasshi 1984;29:121-6.

18 Petridou M, Kimiskidis V, Deligiannis K, Kazis A. Borjeson-Forssman-Lehman syndrome: two severely handicapped females in a family. Clin Neurol Neurosurg, 1997;99:148-50.

19 Kubota T, Oga S, Ohashi H, Iwamoto Y, Fukushima Y. Borjeson-ForssmanLehmann syndrome in a woman with skewed $X$-chromosome inactivation. Am J Med Genet 1999;87:258-61.

\section{CORRECTION}

doi: 10.1136/jmg.2005.031369corrl $\mathrm{n}$ the Original article titled,
Oculocerebrocutaneous syndrome: the brain malformation defines a core phenotype ( $J$ Med Genet 2005;42:913-921) the supplementary figures were missing from the paper. The supplementary figures are available on the JMG website at http:// www.jmedgenet.com/supplemental. 